\title{
Editorial
}

\section{Laparoscopic Sleeve Gastrectomy for the Surgical Treatment of Obesity: Is It an Easy Procedure?}

\author{
Emilio Manno, MD* \\ Bariatric and Metabolic Surgery Unit, Department of Surgery, Ospedale Cardarelli, Naples, Italy \\ "Corresponding author \\ Emilio Manno, MD \\ Head Surgeon, Bariatric and Metabolic Surgery Unit, Department of Surgery, Ospedale Cardarelli, Naples, Italy; E-mail: mannoemilio@gmail.com
}

\section{Article information}

Received: September $4^{\text {th }}, 2020$; Accepted: October $9^{\text {th }}, 2020$; Published: October $13^{\text {th }}, 2020$

\section{Cite this article}

Manno E. Laparoscopic sleeve gastrectomy for the surgical treatment of obesity: is it an easy procedure? Surg Res Open J. 2020; 6(I): el. doi: I0.17। 40/SROJ-6-e004

$\mathrm{L}$ aparoscopic sleeve gastrectomy (LSG) is currently the most performed bariatric procedure in the world. The $4^{\text {th }}$ International Federation for the Surgery of Obesity and Metabolic Disorders (IFSO) Global registry report (2014-18) estimates 87,015 procedures, equal to $45.9 \%$ of all bariatric procedures. Initially performed as the first step of the duodenals witch (biliopancreatic diversion with duodenal switch (BPD-DS)), a very complex malabsorptive procedure invented by a Canadian Surgeon P. Marceau as an evolution of the BPD, invented by N. Scopinaro, an Italian surgeon, LSG established itself in the early 2000s as a stand alone procedure, especially following the observations of Michael Gagner, pioneer of bariatric surgery. Over the years LSG has grown rapidly. The reasons for this popularity are the relative technical simplicity compared to other procedures, efficacy, good quality. For these reasons there has been a real explosion of bariatric surgery: many surgeons, driven by the relative simplicity of the procedure (longitudinal gastrectomy on the guide of a probe), begun to propose this procedure. So is LSG really an effective simple procedure that is good for all patients? Absolutely not. Performing a longitudinal gastrectomy can be simple; performing a good LSG is not. The execution of an ideal LSG is essentially determined by three factors:

\section{Adequate Background in Bariatric Surgery}

Laparoscopic sleeve gastrectomy (LSG) is certainly an effective intervention, but not all obese patients can be treated with this procedure. For about two years there have been more and more reports of increased incidence of Barrett's esophagus in operated patients, and of de novo gastroesophageal reflux disease (GERD). This is probably determined by an inaccurate selection of the patient: the correlation between syntopathology and gastroscopy signs during the pre-operative study and the worsening of symptoms after surgery is now certain A surgeon must therefore have multiple treatment solutions to be able to define himself a bariatric surgeon

\section{Adequate Training to Minimizes the Risk of Complications}

Leak coming from the "new" stomach is a dramatic event, with a high risk of mortality. It is now well documented that early leaks depend mostly on surgical technique errors.

Starting from this analysis it is essential that anyone who wants to perform LSG safely must know what is the correct indication, how to correctly perform it, how to minimize the risk of complications.

In the era of Coronavirus disease 2019 (COVID-19), the use of the webinar is even more a safe and effective means to explore topics like the one we talked about. 